\title{
Use of drugs and antibiotics in poultry production in Ghana
}

\author{
P. K. TURKSON \\ Department of Animal Science, School of Agriculture, University of Cape Coast, Cape Coast, \\ Ghana
}

\section{ABSTRACT}

This study was designed to assess the extent of drug and antibiotic use in small and large commercial poultry producers in Ghana, and the extent of the knowledge, perceptions and practice of drug withdrawal period in poultry production. In all, 483 poultry farmers in Greater Accra, Ashanti and Central regions were interviewed using a prepared questionnaire. The sources of knowledge of which drug to buy and proportions of farmers that used such sources were personal experience, 33.3 per cent $(\mathrm{n}=481)$; veterinarians, 21.4 per cent; veterinary technicians, 20.6 per cent; drug sellers or shops, 18.7 per cent; and other farmers, 6.0 per cent. The drugs used by respondents (excluding vitamins and mineral supplements) could broadly be classified as antibacterials (52.0\%, $\mathrm{n}=1559)$, coccidiostats or coccidicidals $(33.7 \%)$, and dewormers $(14.3 \%)$. Among the antibacterials, the tetracyclines formed the largest class $(35.7 \%, \mathrm{n}=831)$, followed by the nitrofurans $(23.1 \%)$, penicillinstreptomycin combinations (18\%), and sulphonamides and sulphonamide combinations $(8.3 \%)$. For the coccidiostats, the largest group comprised drugs with sulphonamides or their combination $(58.4 \%, \mathrm{n}=539)$, followed by those with amprolium and amprolium combinations $(39.1 \%)$. The dewormers were mainly of two classes: those containing piperazine $(50.7 \%, \mathrm{n}=229)$ and those with levamisole $(49.3 \%)$. When asked what they did with eggs when layers were under drug treatment, a significant proportion of respondents $(91.1 \%, \mathrm{n}=426)$ said they sold the eggs. When asked whether they had heard the term "withdrawal period", $47.4 \%(n=479)$ of the respondents replied in the affirmative. The mean $( \pm$ $\mathrm{SE}$ ) days given by respondents (who had heard the term) as the minimum length of the withdrawal period (WP) were $8 \pm 0.4$ days $(n=166)$ for broilers (range 0-28 days with median of 7 days) and $7 \pm 0.4$ days $(n=171)$ for eggs (range 0-26 days with median of 5 days). The reasons given for withdrawal period being unnecessary or impracticable in Ghana were mainly economic or ignorance and lack of knowledge. The study brought out issues on withdrawal period and drug management practices that will help reduce or avoid residues in eggs and meat, and need to be tackled seriously.
\end{abstract}

\section{RÉSUMÉ}

Turkson, P. K.: Usage de médicaments et d'antibiotiques dans l'élevage de volaille au Ghana. Cette étude était destinée à évaluer le degré d'usage de médicaments et d'antibiotiques à pétite et à grande échelle d'éleveurs de volailles au Ghana, et le degré de connaissance, de perspicacité et de pratique de la période de médicament interrompu dans l'élevage de volaille. En tout, 483 éleveurs de volaille dans les régions Greater Accra, Ashanti et Central étaient interviewées avec un questionnaire préparé à l' avance. Les sources d'information de quel médicament à acheter et les proportions d'éleveurs qui comptaient sur telles sources d'information étaient expérience personnelle, $33.3 \%(\mathrm{n}=481)$; vétérinaires, $21.4 \%$; techniciens vétérinaires, $20.6 \%$; revendeurs de médicaments ou les pharmacies agrochimiques $18.7 \%$, et autres éleveurs, $6.0 \%$. Les médicaments utilisés par les interrogées (à l'exclusion de vitamines et de minéral complémentaire) pourraient être classifiés généralement comme antibactériens $(52.0 \%, \mathrm{n}=1559)$, coccidiostats/ coccidicidals $(33.7 \%)$ et les vermifuges $(14.3 \%)$. Parmi les antibactériens, les tétracyclines constituaient les plus grandes catégories $(35.7 \%, \mathrm{n}=831)$ suivi par les nitrofurans (23.1\%), combinaisons pénicilline-streptomycine (18\%) et les combinaisons sulphonamides et sulphonamide $(8.3 \%)$. Pour les coccidiostats le plus grand groupe se composait de médicaments avec sulphonamides ou leur combinaison $(58.4 \%, \mathrm{n}=539)$, suivi par ceux avec les combinaisons amprolium et amprolium (39.1\%). Les vermifuges étaient principalement de deux catégories: ceux contenant piperazine $(50.7 \%, \mathrm{n}=229)$ et ceux avec levamisole (49.3\%). Quand on demandait ce qu'ils faisaient avec les œufs lorsque les pondeuses étaient sous l'effet de traitement de médicament, une proportion considérable de personnes interrogées $(91.1 \%, \mathrm{n}=426)$ disaient qu'ils vendaient les œufs. Quand on demandait s'ils ont entendu l'expression "période de médicament interrompu", $47.4 \%$ $(\mathrm{n}=479)$ de personnes interrogées repondaient affirmativement. Les jours moyens $( \pm \mathrm{SE}$ ) donnés par les personnes interrogées (qui ont entendu l'expression) comme la durée minimum de la période de médicament interrompu (PMI) étaient $8 \pm 0.4$ jours $(n=166)$ pour les poulets de chair (variation $0-28$ jours avec la médiane de 7 jours) et $7 \pm 0.4$ jours $(n=171)$ pour les œufs (variation 0-26 jours avec la médiane de 5 jours). Les raisons données

Ghana Jnl agric. Sci. 41, 23-33 
Original scientific paper. Received 25 Oct 06; revised 18 May 07

\section{Introduction}

Poultry production in developing countries is beset by high mortality of birds. The risk of losses from high mortality is real and cannot be afforded by the small-scale operators with holding capacities of less than 100 birds who dominate commercial poultry production in Ghana (World Bank, 1992). Therefore, farmers have resorted to drugs and antibiotics for preventive and curative purposes to minimize losses. Some prevalent poultry diseases in Ghana include Newcastle disease, Gumboro disease, fowlpox, Marek's disease, colisepticaemia, helminthiasis, coccidiosis, and avian salmonellosis (Pullorum disease and fowl typhoid).

A major concern in public health is the use of antimicrobials/antibiotics in poultry production (World Health Organization, 2004). Antimicrobial agents have been used for therapy, as well as in animal feed to increase growth rates, improve feed conversion and reduce mortality and morbidity (Bird, 1968; Visek, 1978). The benefits of antibiotics in food production at sub-therapeutic levels include improvement in growth rate and efficiency of feed utilization, reduction in mortality and morbidity, and improvement in reproductive performance (Maritz, 2001). At high levels for prophylaxis and therapy, antibiotics help to prevent disease in exposed animals and to treat diseases (Cromwell, 1999). Furthermore, antibiotics help to improve safety of food because healthy animals result in a safer food supply through the reduction and elimination of certain pathogens. They also reduce the cost and improve the quality of food production through the more efficient use of natural resources critical to meeting the increasing nutritional and protein que la période de médicament interrompu n'étaient pas nécessaire ou bien impracticable au Ghana étaient surtout économique ou l'ignorance/manque de connaissance. L'étude a soulevé les questions sur la période de médicament interrompu et les pratiques de contrôle de médicament qui serviront à réduire ou à éviter les résidus dans les œufs et la viande et exigent d'être abordées sérieusement.

needs of a growing global population. Antibiotics also improve animal well-being because animals become healthier as a result of the diseasesuppressing effects of antibiotics.

However, arguments against the use of antimicrobial agents in animal production are several. The therapeutic use of antimicrobial agents is thought to have resulted in the development of an increasing number of resistant pathogenic bacteria (Moellering, 1990). Antibioticresistant patterns have been linked with Enterococcus sp. isolated from poultry production environments, and this bacterium is suspected to be a potential vector in accumulating and disseminating antibiotic resistance from the animal environment to man through food supply (English et al., 2000). Also, encouraged by drug sales efforts, economic pressures, and easy access to products, animal owners have frequently used and abused antibiotics in an effort to solve disease problems (Rice \& Erickson, 1986). Turkson (2000) noted that misuse of drugs in Ghana is likely to increase the chance of development of drug resistance.

Apart from resistance, it is thought that the improper use of antibiotics may result in delayed diagnosis, ineffectiveness, toxicity (poisoning), allergic reactions and drug residues contaminating food animal products, which may prove in the end to be costly and detrimental (Rice \& Erickson, 1986). It has been argued that drug residues have led to hypersensitivity to sunrays and other allergies, bone marrow depression, carcinogenesis, and drug resistance (Neondo, 2002). Also, drug residues in the food industry may threaten human health by being acutely and cumulatively allergenic, toxic, mutagenic, 
teratogenic, or carcinogenic (Federation of Veterinarians in Europe, 2003).

A campaign now restricts the use of antimicrobials in animal production as a result of the perceived harmful effects of these antimicrobials in man. The appearance of multiple resistances to antibiotics in human pathogens has shifted attention to human and veterinary use of these valuable medicines (Federation of Veterinarians in Europe, 2003). Gyening (1986) reported evidence of the development of tetracycline resistance in some bacteria in the poultry industry in Ghana as a result of farmers resorting to underdosing because of high prices of drugs. Reasons advanced by McMullin (2000) for the need to ban antibiotic use in animals include a) increasing resistance to antibiotics used in human medicine, b) absence of new classes of antibiotics over the past decade, and c) increasing numbers of patients in intensive care suffering from immune deficiencies. The concerns over veterinary drug use and residues have increased lately in developing countries because of the need to meet requirements for international trade, especially after detecting trace elements of chloramphenicol, nitrofurans in animal products (FAO/WHO, 2004; Cannavan, 2004).

This paper aims to assess the extent of drug and antibiotic use in small and large commercial poultry producers in Ghana, and the extent of the knowledge, perceptions and practice of drug withdrawal period in poultry production. This could form the basis for extension packages for farmers on the judicious and prudent use of drugs and antibiotics in poultry production in Ghana.

\section{Materials and methods}

The study was conducted in the Greater Accra, Ashanti and Central regions. The specific areas selected were Accra Metropolis, Tema Municipality, Kumasi Metropolis and surrounding districts, Agona and Awutu-Effutu-Senya districts. These places were chosen purposively because, between them, they have the largest concentration of small and large-scale poultry producers in Ghana.

The sampling frame was all small and largescale poultry producers in the defined areas. In some instances, a list of flock owners kept by the Ministry of Food and Agriculture or the poultry farmers association was used as the starting point. In other places where there was no sampling list, the snowball method for data collection was used. In this procedure, farmers who were interviewed gave the names of other poultry farmers in their locality; and they were then interviewed. A total of 483 poultry farmers were interviewed.

A questionnaire was prepared, pre-tested, and used as the data-collecting instrument. The questionnaires were administered by five 3 -year university agriculture students in the selected localities. The questions related to the background of the farms and respondents, issues on types of drugs used and respondents' perceptions on withdrawal period for antibiotics. The questionnaires were administered on the farms or at veterinary clinics when farmers went to collect vaccines, twice a week. The study was done over a 3-month period between July and September 2002.

Data were analyzed using Statistix ${ }^{\circledR}$ after entry using Excel@. Quantitative data were summarized using descriptive statistics and percentages, while qualitative data were collated and tallied manually.

\section{Background \\ Results}

The regional distribution of the respondents was as follows: Greater Accra, 38.7 per cent $(n=483)$; Ashanti, 41.8 per cent; and Central, 19.5 per cent.

The educational background of the respondents was as follows: no education, 10.3 per cent ( $n=476)$; basic, 26.1 per cent; secondary or vocational, 43.1 per cent; and post-secondary or tertiary, 20.6 per cent.

The types of production systems practiced and the proportions of respondents using each were as follows: "All-in, all-out", 34.8 per cent ( $n=466)$; continuous, 63.5 per cent; and others, 1.7 per cent. Table 1 gives the descriptive statistics 
TABLE 1

Numbers of birds kept by respondents between June 2001 and June 2002

\begin{tabular}{lrrrr}
\hline & Broilers & Layers & Cockerels & $\begin{array}{c}\text { Day-old } \\
\text { chicks }\end{array}$ \\
\hline $\mathrm{n}$ & 296 & 398 & 75 & 44 \\
Mean & 1270 & 2512 & 1550 & 2870 \\
SE (Mean) & 156 & 364 & 310 & 418 \\
Median & 600 & 1000 & 500 & 2000 \\
Minimum & 50 & 5 & 20 & 20 \\
Maximum & 37000 & 110,000 & 15000 & 12000 \\
\hline
\end{tabular}

for the flock holdings of respondents between June 2001 and June 2002.

\section{Drug and antibiotic use}

Knowing which drug to buy and use for a problem in poultry is essential. The sources of knowledge of which drug to buy and proportions of farmers that used such sources were as follows: personal experience, 33.3 per cent $(n=481)$; veterinarians, 21.4 per cent; veterinary technicians, 20.6 per cent; drug sellers or shops, 18.7 per cent; and other farmers, 6.0 per cent.

The drugs used by respondents (excluding vitamins and mineral supplements) could broadly be classified as antibacterials $(52.0 \%, \mathrm{n}=1559)$, coccidiostats or coccidicidals $(33.7 \%)$, and dewormers $(14.3 \%)$. Among the antibacterials, the tetracyclines formed the largest class $(35.7 \%$, $\mathrm{n}=831$ ), followed by the nitrofurans $(23.1 \%)$, penicillin-streptomycin combinations (18\%), and sulphonamides and sulphonamide combinations $(8.3 \%)$. For the coccidiostats, the largest group comprised drugs with sulphonamides or their combination $(58.4 \%, \mathrm{n}=539)$, followed by those with amprolium and amprolium combinations (39.1\%). The dewormers were mainly of two classes: those containing piperazine $(50.7 \%$, $\mathrm{n}=229)$ and those with levamisole $(49.3 \%)$.

The regional distribution of veterinary drug businesses (selling all types of drugs not necessarily restricted to poultry drugs) in Ghana was as follows: Greater Accra, 34.3 per cent $(n=102)$; Ashanti, 21.6 per cent; Volta, 10.8 per cent; Western, 9.8 per cent; Brong-Ahafo, 7.8 per cent; Central, 3.9 per cent; Eastern, 3.9 per cent; Northern, 3.9 per cent; Upper-West, 2 per cent; and Upper-East, 2 per cent.

When asked what they did with eggs when layers were under drug treatment, a significant proportion of respondents $(91.1 \%, \mathrm{n}=426)$ said they sold the eggs, with 3.5 per cent saying they destroyed or threw away the eggs, and 5.4 per cent saying they gave such eggs away to feed pigs.

Asked whether eggs should be eaten when layers were on antibiotic treatment, 79.3 per cent $(n=425)$ said 'Yes'. The reasons given for the affirmative answer included the following:

- 'Drugs do not have any effect on eggs'.

- 'We cannot afford to throw eggs away'/ 'We need money'/ 'It is not economical to destroy eggs'.

- 'Some antibiotics are used in man, so it is healthy to eat the eggs.'

- 'Antibiotics are not poisonous'.

- 'Is there anything wrong?'

- 'I do not think it is harmful'/ 'I do not see anything wrong with it since farmhands and a lot of people have been eating such eggs for a long time and nothing has happened to them.'

For those who answered in the negative, some of the reasons given included:

- 'Drug residues in the eggs may have effect on the consumer'.

- 'Such eggs may have the taste of antibiotics.'

- 'Veterinarians say it is not good for consumption'.

When asked whether broilers on antibiotic treatment could be slaughtered for consumption within a few days (about 3 days) after stopping treatment, 64.3 per cent ( $n=392)$ said 'Yes'. Among the reasons given for the affirmative answer were the following: 
- 'Three days are enough for the drug to be broken down'/ 'There is nothing wrong with the meat.'

- 'I do not think it is harmful.'

- 'Antibiotics cannot kill even if they are still in the body.'

- 'There is no effect of the drug in man.'

- 'It depends on the drug used.'

Those answering 'No' gave reasons including the following:

- 'The carcass could be poisonous.'

- 'I have been told not to eat it, but I do not know why.'

- 'The carcass quality or taste is reduced / affected by the accumulation of the drug.'

- 'Antibiotic scent can be smelt in meat.'

- 'There might be residues/remnants in the meat and blood.'

- 'It is only after 7 days that it can be eaten.'

- 'It is not good for consumption.'

\section{Withdrawal period}

When asked whether they had heard the term "withdrawal period", 47.4 per cent $(n=479)$ of the respondents replied in the affirmative. Of these, 58.1 per cent $(n=227)$ were able to explain what withdrawal period is. Among the explanations thought correct were the following:

- 'It is the period within which the poultry product is not safe for consumption.'

- 'It is the interval between treatment and consumption of poultry products.'

- 'It is the duration in which birds are given plain water after antibiotics have been given so that drugs can be cleared out of the meat.'

- 'It is the period allowed for the accumulated drugs in the birds to get out of their system.'

- 'It means that when I am using any antibiotic, there is a period that I have to wait before selling the eggs.'

- 'It is the period between the time you stop administering the drug and the time you start selling the products.'

- 'It is when birds are put on plain water after treatment to reduce drug residues.'
Some explanations that were incorrect included:

- 'It is a manufacturer's instruction on the drug label.'

- 'It is the prescription from the manufacturer to keep the texture and wholesomeness of the chicken.'

- 'It is when birds are allowed time to recover from a disease.'

- 'I saw it on a label of a drug I bought.'

The mean $( \pm \mathrm{SE})$ days given by respondents (who had heard the term) as the minimum length of the withdrawal period (WP) were $8 \pm 0.4$ days $(\mathrm{n}=166)$ for broilers (range $0-28$ days with median of 7 days), and $7 \pm 0.4$ days ( $n=171)$ for eggs (range 0-26 days with median of 5 days).

\section{TABLE 2a}

Factors With Significantly Higher Proportions of Respondents Who Considered or Would Consider Withdrawal Period as:

\begin{tabular}{lcc}
\hline Factor & $n$ & $\%$ \\
\hline Good & 483 & 89.6 \\
Advisable & 483 & 83.4 \\
Part of drug management practices & 481 & 83.2 \\
Necessary & 479 & 81.8 \\
Appropriate & 481 & 80.9 \\
Responsibility of poultry producer & 482 & 79.5 \\
To be adhered to sometimes & 483 & 72.5 \\
Foreign to Ghanaians & 483 & 64.0 \\
Wasteful & 482 & 62.4 \\
A right of the consumer & 482 & 58.5 \\
\hline
\end{tabular}

TABLE $2 b$

Factors With Significantly Higher Proportions of

Respondents Who Considered or Would Consider Withdrawal Period as:

\begin{tabular}{lcc}
\hline Factor & $n$ & $\%$ \\
\hline Not enforceable in Ghana & 482 & 85.5 \\
Uneconomical & 480 & 83.3 \\
Not mandatory in Ghana & 480 & 80.0 \\
Not to be adhered to always & 483 & 72.5 \\
Not critical & 482 & 70.7 \\
Impracticable in Ghana & 481 & 67.4 \\
\hline
\end{tabular}


Tables $2 \mathrm{a}$ and $2 \mathrm{~b}$ show the proportions of respondents giving their perceptions on factors affecting practice of withdrawal period.

The respondents gave reasons concerning whether WP was necessary or practicable in poultry production in Ghana. Among the reasons given for WP being necessary in Ghana were the following:

- 'To ensure public safety as antibiotics and other drugs can affect humans in diverse ways.'

- 'To reduce drug residues in birds.'

- 'To prevent drugs from being transferred to man.'

- 'It is part of manufacturer's instructions.'

- 'It will control the rate at which drugs are being used in the country.'

- 'It restores the natural taste of meat or egg'/ 'The taste of the carcass is affected if it is not done.'

- 'To ensure safe and quality production of eggs and meat.'

The reasons given by those who perceived WP as unnecessary included:

- 'It is not economical'/ 'It will let farmers lose a lot of money.'

- 'Some drugs have no withdrawal period.'

- 'It is a waste of time because people are willing to buy eggs produced'/'I will lose to a ready market if I observe it.'

- 'It does not make a difference.'

- 'In Ghana so far there are no documented cases of drug problems.'

- 'For the past years nobody has said anything concerning withdrawal period and there is no evidence for not practicing it.'

- 'Drugs used in Ghana have no residual effect.'

- 'People won't abide by it even if made compulsory and required by law.'

Many reasons were given why WP was impracticable in Ghana, among which were the following:

- 'The government does not give any subsidy.'
- 'There is no compensation for destroying produce like egg and meat.'

- 'High cost of production does not allow farmers to afford to practice this.'

- 'Most farmers are poor.'

- 'There is economic hardship.'

- 'There is ignorance, and little or no education.'

- 'It is not economical.'

- 'Many people do not practice it.'

- 'High rate of semi-literacy makes it impossible.'

- 'Farmers would not do it.'

- 'It is expensive or wasteful.'

- 'It is not a law in Ghana.'

- 'It is not easy to wait when market demand is high.'

- 'In Ghana nobody cares about the health of consumers.'

- 'There is no side effect if it is not done, so why worry?'

- 'Nobody is practicing it in Ghana.'

- 'We have not been educated on it.'

Cross tabulations of some factors affecting the practice of WP showed interesting information that could support some reasons given above. The results were as follows:

- 72.8 per cent $(n=478)$ of respondents perceived WP to be necessary and a responsibility of the farmers (compared to $11.3 \%$ who perceived it to be unnecessary and not the farmers' responsibility).

- 72.3 per cent $(n=477)$ of respondents perceived WP to be necessary and should be part of drug management (compared to $9.6 \%$ who perceived it to be necessary but not part of drug management).

- 64.3 per cent $(n=476)$ of respondents perceived WP to be necessary but not mandatory (compared to $17.7 \%$ who perceived it to be necessary and mandatory).

- 55.0 per cent $(n=478)$ of respondents perceived WP to be necessary but not critical (compared to $26.8 \%$ who perceived 
it to be necessary and critical).

- 55.5 per cent $(n=479)$ of respondents perceived WP to be necessary but should not be adhered to always (compared to $26.3 \%$ who perceived it to be necessary and to be adhered to always).

- 77.6 per cent $(n=481)$ of respondents perceived WP to be good and appropriate (compared to $9.1 \%$ who perceived it not to be good and inappropriate).

- 61.6 per cent $(n=482)$ of respondents perceived WP to be good but not critical (compared to $25.0 \%$ who perceived it to be good and critical).

- 75.0 per cent $(n=480)$ of respondents perceived WP to be good but not economical (compared to $14.6 \%$ who perceived it to be good and economical).

- 58.6 per cent $(n=481)$ of respondents perceived WP to be good but not practicable (compared to $39.0 \%$ who perceived it to be good and practicable).

- 53.9 per cent $(n=482)$ of respondents perceived WP to be good but wasteful (compared to $35.7 \%$ who perceived it to be good and not wasteful).

- 71.5 per cent $(n=481)$ of respondents perceived WP to be the responsibility of producers and part of drug management (compared to $11.6 \%$ who perceived it not to be the responsibility of the producer but part of drug management).

\section{Discussion}

About 90 per cent of the respondents had had basic education or higher. They were literate enough to be able to read and understand instructions and literature on drugs. These people could be targeted with packaged extension material on prudent and judicious use of antimicrobials.

The continuous production system was more common, because it allowed all-year-round use of facilities, rather than having "down-times" as prescribed in the "all-in, all-out" system. Farmers desire to maximize use of their resources; so any system that requires a fallow period is unattractive.

Table 1 shows that the median numbers of flock holdings were small, lending support to the observation that poultry production in Ghana is dominated by small-scale operators (World Bank, 1992). Poultry production is on the decline in Ghana because of high cost of production and competition from low-priced imported poultry products (Yankah, 1994).

About 40 per cent of the respondents in the study relied on personal experience or experience of other farmers concerning what drugs to buy for problems in their flocks. Although farmers may be experienced in handling and storage of drugs, they lacked professional expertise to determine the ethical use, dosage rates, route of administration, and quality of drugs; and this could result in diseases not being treated costeffectively (Veterinary Services DirectorateGhana, 2002). Rice \& Erickson (1986) observed that although the actual administration of medicines may not seem difficult, the activity of the drug within the living animal is very complex and can adversely affect the animal, its products and the consumer. Therefore, veterinary advice should be sought regarding use and compatibility of drugs.

The expertise of veterinarians or veterinary technicians was used by about 42 per cent of the respondents. Another study reported that just about 51 per cent of information on veterinary drugs to farmers was given by veterinary personnel (Veterinary Services Directorate-Ghana, 2002). Lack of accessibility to veterinary personnel was given as one reason for this. Veterinary Services Directorate-Ghana (2002) reported that poultry farmers in southern Ghana tended to administer drugs by themselves because of their high rate of literacy; and also used drugs daily, which could be demanding when skilled veterinary professionals were employed. About 19 per cent of the respondents in this study used drug sellers and shop attendants as sources for information. The competence of such people is 
questionable because they have not been trained adequately for this role.

Antibiotics, coccidiostats or coccidicidals, and dewormers were the three major classes of drugs commonly used, indicating the importance of problems involving bacterial infections, coccidiosis and worm infestations in poultry production in Ghana. The antibiotics were more commonly used compared to the others. Tetracyclines were usually used, followed by nitrofurans, penicillin-streptomycin combinations and sulphonamides, raising fears of residues and resistance which could be passed on to humans. Reports from Kenya indicated that the most common residues in milk, eggs and meat of various types of animals were from tetracyclines, chloramphenicols and deworming agents (Neondo, 2002). It had been observed that meat, milk, eggs and broilers marketed in Kenya from Kenyan farmers contained antibiotic residues so that consumers developed allergies, and an increasing antibiotic drug resistance was recorded (Neondo, 2002). The development of tetracycline resistance has been reported in some bacteria in poultry in Ghana (Gyening, 1986).

Accessibility to drugs and antibiotics by poultry farmers is not a major problem. Turkson (2000) reported that improved accessibility to drugs has been attributed to liberalising veterinary drug marketing in Ghana. The ready availability of these drugs without prescription may be contributing to the high rates of use and abuse in some cases. A survey in Ghana showed that 43 per cent of livestock owners buy drugs without prescription for self-medication. It advocated a system in which antibiotics and vaccines should be purchased with prescription (Veterinary Services Directorate-Ghana, 2002).

Information on what is done with eggs when layers are under treatment with drugs was worrying. A significant proportion of the respondents sold eggs to unsuspecting consumers. Several reasons given for sale of such eggs bordered on ignorance of effects of drugs and antibiotics in man, lack of information, and unwillingness to lose money. Similar reasons were given for slaughtering broilers for consumption about 3 days after stopping antibiotic treatment. The reasons for not consuming eggs from layers on antibiotic treatment or meat from broilers could be consolidated and used for extension messages. One of the reasons given was the scent or taste of antibiotics in meat or eggs. How true this is could not be established.

To protect consumers, the Federal Drug Agency of the United States has established maximum antibiotic levels that can be used in animal feeds, and a minimum interval between the last use of antibiotics and slaughter of treated animals, allowing for antibiotic elimination before animals are slaughtered (Knutson \& Hillers, 2001). The WP has been defined as the period after the cessation of treatment during which an animal and its products should not be used for food (Veterinary Medicines Directorate-UK, 1997). The minimum WP applied for eggs and milk is 7 days while that for meat from poultry and mammals is 28 days (Veterinary Medicines Directorate-UK, 1998). However, this depends on the drug. Some coccidiosis-prevention medications have a zeroday drug WP (Chicken Farmers of Canada, 2002). The mean $( \pm \mathrm{SE})$ days given by respondents (who had heard the term) in this study as the minimum length of the WP were $8 \pm 0.4$ days for broilers and $7 \pm 0.4$ days for eggs. Whereas the period stated for eggs was acceptable, that for broilers was too short, raising concerns about risk of residues. Specific established requirements are lacking in Ghana, but it is assumed that standards established in the Codex Alimentarius and internationally apply.

The proportion of respondents who had heard the term "withdrawal period" and could explain it correctly was low $(27.5 \%, \mathrm{n}=479)$. Some respondents identified ignorance and little or no education as being responsible for this. Generally, for those who explained it correctly, their explanations showed clear understanding of the concept of WP. For those who were unable to explain it well, WP was more of a term or 
instruction on drug labels and they did not understand it. This supports the need for extension information to educate poultry farmers that failure to practice WP could result in illegal residues in meat and eggs.

In general, significant proportions found the practice of WP as appropriate, advisable, good, necessary, a right of the consumer, to be adhered to sometimes but not always, part of the drug management practices of the farmer, and a responsibility of the poultry producer. However, some respondents considered WP as wasteful, foreign to Ghanaians, uneconomical, not critical, impracticable, and not enforceable in Ghana. These perceptions could form the basis for preparing extension messages to counter any wrong impressions.

The reasons given for the necessity of WP bordered on preventing drug residues in eggs and meat to protect human health. This is in line with recommended practices (WHO, 2004). The reasons given for WP being unnecessary or impracticable in Ghana could be grouped into two classes: economic and ignorance or lack of knowledge. Some respondents summed the latter up by saying, "I do not see anything wrong with it since farmhands and a lot of people have been eating [such] eggs for a long time and nothing has happened to them." To these respondents, the absence of short or medium-term effect of the residues is enough evidence that the drugs are not harmful, but this is untenable.

The absence of compensation for lost revenue for destroying eggs when layers were on antibiotic treatment, or for practicing WP is one major problem that needs to be tackled if WP is to be enforced in Ghana. A general belief and assertion was that if the government is not providing compensation for lost income or subsidy for poultry production, it has no right to tell farmers what to do. However, governments have a moral obligation to protect consumers from potential dangers arising from unacceptable practices likely to endanger public health and food safety.

One solution likely to have a major salutary effect is educating farmers on the judicious and prudent use of antibiotics and dangers associated with misuse and abuse and not observing WP. Maritz (2001) identified five key principles for prudent use of antibiotics to include using antibiotics to complement good husbandry practices for disease prevention, disease treatment and production enhancement, and not as a substitute or compensation for or mask bad farm and veterinary practices; establishing codes for good and best practices, quality assurance and educational programmes to promote the responsible and prudent use of antibiotics; encouraging professional supervision by veterinarians and record keeping, which are essential and critical in the use and control of antibiotic products; using antibiotics for therapeutic purposes for as short a duration as possible, but for as long as needed and at the recommended dosage regimen, with attention being paid to instructions on the label; and continuously monitoring the effects (positive and negative) of antibiotics after their use to adapt the pattern of use promptly and appropriately.

There have been calls for the establishment of surveillance and monitoring systems for testing for veterinary drug residues to support good decision-making and, with other information, help determine whether further risk management actions are needed to address public health risks (e.g. antimicrobial levels expected in risk assessment) and to make timely interventions possible (Aarestrup et al., 1998; Cannavan, 2004; WHO, 2004). It is possible to reduce the necessity for antimicrobials through stringent implementation of good animal husbandry and management and veterinary practices (WHO, 2004). Wallinga et al. (2002) observed that some poultry producers are working hard to provide safer chickens by using better hygiene, by implementing growing or slaughter conditions to lower the levels of pathogenic bacteria on meat, or by avoiding the use of antibiotics which increase the risk of contaminating meat with antibiotic-resistant bacteria. It has been noted that 
an important means of reducing human exposure to antimicrobial-resistant organisms through the food chain is to ensure that, as far as possible, good hygienic practices and Hazard Analysis Critical Control Point (HACCP) principles are observed (WHO, 2004). Furthermore, farmers and veterinarians have a key responsibility to prevent and minimize the antimicrobial resistance that may have an effect on human and animal health. In this study, a significant proportion (72\%) of respondents perceived WP to be the responsibility of the poultry producer and part of drug management practices, emphasising the important role of farmers and veterinarians in use of drugs. This is worthwhile and should be used as one of the basis for educational extension programmes on prudent and judicious use of drugs and antibiotics in poultry production in Ghana.

In conclusion, the study has shown that issues on WP and drug management practices that will help reduce or avoid residues in eggs and meat are critical and need to be tackled seriously. This can be realised by providing extension education to farmers on the judicious and prudent use of antibiotics and drugs in the poultry industry.

\section{Acknowledgement}

The author gratefully acknowledges the support of Ms Stella Ampiah and Messrs Kofi Nti, Eric Asumang, Emmanuel Mpianing, and Emmanuel Quartey in collecting the data from various locations. He is also indebted to the various respondents for spending time on the questionnaires.

\section{REFERENCES}

Aarestrup, F. M., Bager, F., Jensen, N. E., Madsen, M., Meyling, A. \& Wegener, H. C. (1998) Surveillance of antimicrobial resistance in bacteria isolated from food animals to antimicrobial growth promoters and related therapeutic agents in Denmark. APMIS 106, 606-622.

Bird, H. R. (1968) Effectiveness of antibiotics in broiler feeds. Wld Poult. Sci. J. 24, 309-313.

Cannavan, A. (2004) Capacity building for veterinary drug residue monitoring programmes in developing countries. Report on Joint FAO/WHO Technical Workshop on Residues of Veterinary Drugs Without ADI/MRL, 24-26 August 2004, Bangkok, Thailand. pp. 43-47.

Chicken Farmers of Canada (2002) Medication withdrawal periods. The Chicken Farmer 4, 9.

Cromwell, G. L. (1999) Safety issues, performance benefits of antibiotics for swine examined. Feedstuff. $18 \mathrm{pp}$.

English, L. L., Hayes, J. R., White, D. G., Joseph, S., Carr, L. E. \& Wagener, D. D. (2000) Susceptibility of Enterococcus isolates from the poultry production environment. Food and Drugs Administration Forum, Washington DC. pp. 1-3.

FAO/WHO (2004) Executive summary. Report on Joint FAO/WHO Technical Workshop on Residues of Veterinary Drugs Without ADI/MRL, 24-26 August 2004, Bangkok, Thailand. 5 pp.

Federation of Veterinarians in Europe (2003) Antibiotic resistance and prudent use of antibiotics in veterinary medicine. www.poultry-health.com/ library/antimicrobials/antfve99.htm. Accessed on 17th March 2003.

Gyening, K. O. (1986) Animal health control in Ghana. Proceedings of the 5th Conference of Institutes of Tropical Veterinary Medicine, Kuala Lumpur, Malaysia. pp. 105-106.

Knutson, D. \& Hillers, V. (2001) Antibiotics for animals. The National Dairy Database, USA.

Maritz, J. (2001) Antibiotic in livestock and poultry. www.afma.co.za/AFMA_Templatel 1,2491,7932_2621,00.html. Accessed on 15th September 2005.

McMullin, P. (2000) The future of antimicrobial growth promoters: Alternatives for poultry production in the new millennium. Int. Poult. Prod. 8 (7), 30.

Moellering, R. C. (1990) Interaction between antimicrobial consumption and selection of resistant bacterial strains. Scand. J. Infectious Dis. 70, 1824.

Neondo, H. (2002) Drug residues in animal products, says research. All Africa News Agency Bulletin 38$02(\mathrm{C})$.

Rice, D. N. \& Erickson, E. D. (1986) Antibiotic use in animals. NebGuide G86-795-A.

Turkson, P. K. (2000) Implications of the liberalization of veterinary drug marketing in Ghana. Trop. Anim. Hlth Prod. 33, 43-47.

Veterinary Medicines Directorate-UK (1997) The 
work of VMD: Safety, quality efficacy. The Veterinary Medicines Directorate, UK. 13 pp.

Veterinary Medicines Directorate-UK (1998) The Medicines (Restrictions on the administration of veterinary medicinal products) Regulations 1994 (SI 1994/2987) as amended by SI 1997/2884. Guidance to the Veterinary Profession. AMELIA 8 The Veterinary Medicines Directorate, UK. 13 pp. Veterinary Services Directorate-Ghana (2002) Market survey on access of veterinary drug distribution to farmers. Report submitted to Pan African Programme for the Control of Epizootics (PACE). Nairobi, Kenya. 25 pp.
Visek, W. J. (1978) Mode of growth promotion by antibiotics. J. Anim. Sci. 46, 1437-1446.

World Bank (1992) Staff appraisal report. Republic of Ghana. National Livestock Services Project. Report No. 11058-GH. The World Bank, Washington DC. 132 pp.

WHO (2004) Second Joint FAO/OIE/WHO Expert Workshop on Non-human Antimicrobial Usage and Antimicrobial Resistance: Management Options. Report No. WHO/CDS/CPE/ZFK/2004.8.

Yankah, E. H. T. (1994) What farmers expect of the government. Proceedings of Ghana Animal Science Association Symposium 22, 23-24. 